\title{
Article \\ ICT Motivation in Sixth-Grade Students in Pandemic Times-The Influence of Gender and Age
}

\author{
Pablo Dúo-Terrón, Antonio-José Moreno-Guerrero * (D) and José-Antonio Marín-Marín
}

check for updates

Citation: Dúo-Terrón, P.; Moreno-Guerrero, A.-J.; Marín-Marín, J.-A. ICT Motivation in Sixth-Grade Students in Pandemic Times-The Influence of Gender and Age. Educ. Sci. 2022, 12, 183. https://doi.org/ 10.3390/educsci12030183

Academic Editors: Maria Meletiou-Mavrotheris,

Konstantinos Katzis,

Angelos Sofianidis, Nayia

Stylianidou and Panagiota

Konstantinou-Katzi

Received: 6 February 2022

Accepted: 4 March 2022

Published: 6 March 2022

Publisher's Note: MDPI stays neutral with regard to jurisdictional claims in published maps and institutional affiliations.

Copyright: () 2022 by the authors Licensee MDPI, Basel, Switzerland. This article is an open access article distributed under the terms and conditions of the Creative Commons Attribution (CC BY) license (https:// creativecommons.org/licenses/by/ $4.0 /)$.

\author{
Department of Didactics and School Organisation, University of Granada, 51001 Ceuta, Spain; \\ pabloduo@correo.ugr.es (P.D.-T.); jmarin@ugr.es (J.-A.M.-M.) \\ * Correspondence: ajmoreno@ugr.es
}

\begin{abstract}
Information and communication technology (ICT) is being immersed in people's daily lives at an increasingly younger age. It has been key for adolescents to pursue distance education, and their use and mastery of technological means and tools with Internet access has increased. In this study, the motivation, specifically in the interest, digital competence, autonomy, and social interaction, generated by ICTs in the daily lives of adolescents during the pandemic caused by COVID-19 was analyzed. In the study, the objective was to study the motivation, use and commitment generated by ICTs in these students in relation to their gender and age after their confinement to the classroom caused by the first wave of incoming students. An experimental method of descriptive and correlative design was used along with a quantitative method to analyze the data. The data were obtained in the year 2020 through a validated questionnaire committed to the ICT scale used by PISA (Programme for International Student Assessment). A total of 924 students from the sixth grade of primary education in the autonomous city of Ceuta (Spain), aged between 10 and 13, participated in the sample. The results reveal that the motivation and commitment to ICT in these age groups were medium in relation to the total mean of results on a Likert- 5 scale. Boys scored higher in all the variables analyzed, and both age and gender show correlations, in addition to the factor of prediction. In conclusion, students in the sixth year of primary education, after the confinement period, were medium-high in their use and engagement of ICT. In addition, gender and age affected ICT use and engagement.
\end{abstract}

Keywords: ICT; motivation; gender; age; primary education

\section{Introduction}

The use of electronic tools and devices with internet access is becoming increasingly prevalent in society [1,2]. Currently, information and communication technology (ICT) is being incorporated into everyday routines among adolescents and children, both in schools and in the home [3]. The COVID-19 pandemic has illustrated the importance of knowing how to use and manage different technologies for communication, in both family and school settings [4]. During this period, students made more frequent use of smart devices, compared to the pre-pandemic period [5]. Furthermore, they learned to manage ICT and Internet resources independently, without prior knowledge, without specific subjects, and without the support of teachers [6,7]. This fact indicates that ICT [8] is promoting motivation and commitment during the primary education stage with technological devices such as computers, laptops, tablets, and smartphones [9]. The skills that come into play with the use of these ICT devices and resources are at present a normalized fact [10]. Young people use them to communicate with each other and to express themselves [11].

Although there is no clear idea of what working conditions and levels of science and technology await students in the future [12], inequalities in the access to and use of ICTs are now being perceived. This is currently a matter of great concern. The importance of integrating digital competence in the education of adolescents goes beyond the barriers 
of the school [13]. This is why there is talk of the so-called digital or technological divide between those students who use ICT in one or more domains such as school and/or family [14]. Theoretical attempts to understand the dynamics of these inequalities are scarce and have generated little scientific knowledge $[15,16]$. However, research is more focused on the substantial development of digital technologies and the requirement of digital literacy of citizens for their working, social, and personal lives [17].

More specifically, in the field of education today, the teaching-learning process in the classroom is unimaginable without the use of ICT [18]. Teachers have the idea that ICT is a didactic tool that allows different approaches, thus increasing, in general, the quality of teaching and learning [19]. This is directly related to the need for students to have a digital competence beyond the mere search for information [20]. ICT literacy is an interdisciplinary competence, which is indispensable for learners [21]. Moreover, the motivation to use ICT is connected to other concepts such as emotions [22] and is valuable in working with vulnerable and disadvantaged groups [23]. Today's students need meaningful learning that is personalized according to their particular characteristics and that allows them to develop successfully in the digital society in which they interact [24].

On the other hand, studies show the influence on the digitally assessed academic performance of students with moderate access, use, and interest in ICT resources, both in and out of school [25]. In turn, the diversity of knowledge and resources generated by technological devices and the Internet have an impact on students' motivation and interest in all areas of their daily lives (at school, in social relations, in the family, accessing information and knowledge, doing homework, finding entertainment, etc.) [26,27]. Thus, ICT has the potential to transform the teaching-learning process and effectively manage the acquisition of new knowledge [28] — that is, with electronic devices and the Internet, a student can learn and reinforce educational content from anywhere. This has generated new opportunities and challenges on educational ideas and practices [29]. On the other hand, the impact of ICT in education can be manifested by the changes that are promoted in the methodology, environment, and content of teaching. It can also have an impact on teacher-student interaction that greatly facilitates teaching and learning [30]. These factors enrich new pedagogical alternatives and provide students with meaningful experiences with enhanced learning opportunities [31].

Access to ICTs and Internet connectivity has grown significantly in recent years. This has encouraged the equal, active, critical, and effective participation of students [32]. However, although the factors that influence gendered career choices in science and technology can be identified as early as primary school [11], the access and motivation generated by ICTs, by age and gender in children aged 10-13 years, can vary across different types of settings $[33,34]$. Thus, girls have different interests in terms of motivation, participation, cooperation, and technological addiction compared to boys [2]. While girls use ICT for educational purposes, boys use it for social interaction practices [35]. However, age and gender are not essential factors in the achievement of educational outcomes related to digital skills [1]. Thus, schools cannot match the social differences related to ICT use at home, as these depend mostly on families themselves at this age [36]. However, they do provide the opportunity for students to be more active and motivated and to improve [36,37].

The effective integration and engagement of ICTs in everyday life play a fundamental role in maintaining social and motivational relationships in digital literacy $[38,39]$, and may even mediate between the interest in technologies and the social engagement that ICTs generate [40]. Adolescents are familiar with some basic concepts related to the use of video games, sharing information, or sending photos and videos to their friends, as part of their daily life [11]. There are multiple factors that intervene in the use of ICTs among adolescents, and these depend on the level of schooling, their economic situation, their digital skills, and their place of residence, as well as the presence of electronic devices in the home [41]. Adolescents with a greater use of electronic devices are more likely to use social networks, although for recreational, in addition to educational, purposes [42,43]. In this sense, online collaboration has the potential to develop digital literacy skills, but it may 
affect children's and adolescents' academic performance [4,43], psychological and social well-being [38], as well as their cognitive-motivational aspect [44].

The main research on the motivation generated by ICT in adolescents is related to education, especially in how the use of ICT in students, at home and at school, influences the performance of reading comprehension [5,45,46], mathematics [47,48] and science [47-50]. In these three domains or areas of knowledge, there are differences in academic performance. During the pandemic, ICT use has grown among adolescents, and they rely more than ever on technology for their studies [51]. Analyzing ICT use and its variables in this period is important, as it provides a clearer picture of the effects on motivation and academic performance in this student body [49]. Such research can create an early warning system that can identify students at risk of not developing adequate reading literacy in the future [45]. In this regard, there are studies linking the easy availability and autonomy of ICT with negative reading achievement, especially at home [5,45]. However, their appropriate use in schools has highly positive effects $[40,43]$. Thus, school autonomy over ICT in countries such as Singapore and Turkey before the pandemic had a positive relationship with achievements in science and mathematics $[47,50]$.

From the different spheres of society, we must promote among students the ease of use of ICTs, which can help motivate, complement, enrich, and transform education [52]. Among the main characteristics of ICT that stand out and are influenced in the field of education are ubiquity [53] and collaborative learning. ICTs improve skills and attitudes that lead to changes in the student, through appropriation in the monitoring role, encouraging the promotion of autonomy and voluntary action in the classroom. This fact produces an important social contribution that evidences protagonist and citizen behavior [54] from a constructivist approach and a collaborative methodology [55].

\section{Justification and Objectives of the Study}

The COVID-19 pandemic has generated a need in education related to the use, learning, and mastery of online ICT [56]. Handling electronic tools and devices, in schools and at home, has generated a need at an early age and requires digital training from schools for the correct use of platforms, resources, or applications. However, young people today use ICT quite frequently and for different purposes, generating different types of motivation and academic performance depending on the gender and age of the students [2,25-27,35]. As a result of this contrast, this research has arisen in order to increase knowledge of the degree of interest, socialization, autonomy, and digital competence generated by ICT in primary school pupils in pandemic times.

The main objective of this research is to learn about the motivation and commitment generated by ICT, at home and at school, in sixth-grade primary school pupils after their incorporation into the classroom, following the confinement of the first wave of the COVID19 pandemic.

This general objective leads to the formulation of the following specific objectives:

- To learn about the motivation aroused in sixth-grade primary school pupils by the use and engagement of ICT during the first wave of confinement;

- To identify the influence of gender on the motivation of sixth-grade primary school students to use ICT after this confinement;

- To determine the influence of age on the motivation of sixth-grade primary school students in the use of ICT after this confinement.

The following research questions arise from these objectives:

- Q1: Which of the variables analyzed have the greatest influence on ICT use?

- Q2: Does gender influence students' motivation to use ICTs after the pandemic?

- Q3: Does the age of the student after confinement influence the degree of motivation and in which areas of study? 


\section{Method}

\subsection{Research Design and Variables}

This research is a quasi-experimental descriptive and correlational study based on a quantitative method in the treatment of data [57].

\subsection{Participants}

The number of students participating in this study was 924, which represented $78 \%$ of the total number of students enrolled in the sixth grade of primary education in the autonomous city of Ceuta (Spain) at the time of the study, according to data provided by the Provincial Directorate of the Ministry of Education and Vocational Training of this city. The population of Ceuta exceeds 85,000 inhabitants, and it stands out for its linguistic and cultural diversity. Thus, $32 \%$ of the inhabitants have Dariya as their mother tongue, a colloquial dialect of Arabic for exclusively oral use that does not have official recognition according to the data provided by the report of the State School Council in 2019 [58].

The questionnaire that the Programme for International Student Assessment (PISA) developed in 2015 was the instrument used in November 2020 for the sample of this study, which was made up of 50.22\% girls and $49.78 \%$ boys, aged between 10 and 13 years, with an average of 11.08 years and a standard deviation of 0.49 .

The study was carried out through a seminar organized by the Provincial Directorate of Education and Vocational Training of the autonomous city of Ceuta and focused on students in the sixth year of primary education. The study was carried out on a voluntary basis in all of the educational centers that teach this stage of education in this city, with the exception of one center, a private-subsidized center that decided not to participate. The total number of participating centers was 22 (public $=17$; subsidized $=5$ ). These data were extracted from the database provided freely by the Spanish Ministry of Education and Vocational Training.

\subsection{Instrument}

A validated questionnaire on ICT motivation, use, and engagement located after a thorough review of the scientific literature [44] was used for the research. The instrument was translated into Spanish by two native speakers specialized in the subject matter of the study. It should be noted that the original instrument was intended for adolescents. In this case, it is still appropriate for the study population of this research.

This questionnaire consists of 21 items distributed in four dimensions: (a) Interest generated by ICT (INT) (6 items); (b) Perceived digital competence through ICT (COM) (5 items); (c) Perceived autonomy through ICT (AUT) (5 items); (d) ICT as a subject of social interaction (SOC) (5 items). (see Appendix A).

The different variables were assessed using a 5-point Likert rating scale $(1=$ Never; 2 = Almost never; 3 = Sometimes; 4 = Almost always; 5 = Always). Regarding age and gender, students were asked to provide these data in writing in the same questionnaire.

The instrument used was based on the instrument validated for the Swiss and German context [44]. In our case, based on the metric values of the validation and reliability of this instrument, we have validated and made the instrument reliable in the Spanish context. In this case, the instrument was translated. This was carried out by two translation experts. Subsequently, the Delphi method [59] was used quantitatively, with the judgement of six experts in the field of education and in the use of ICT for its review. In addition, various statistical procedures were carried out to check the adequacy and correspondence of the experts' observations, using Fleiss' Kappa and Kendall's W tests, which proved to be adequate $(\mathrm{K}=0.83 ; \mathrm{W}=0.87)$.

Quantitative validation was carried out by means of an exploratory factor analysis, using the principal component method with a Varimax rotation. Dependence between variables was obtained with the sphericity test (Bartlett $=4671.62 ; p<0.001)$. In addition, the Kaiser-Meyer-Olkin test found a relevant score $(\mathrm{KMO}=0.93)$ on sample adequacy. Finally, the average reliability of the questionnaire was calculated with different statistical 
methods such as composite reliability $(\mathrm{FC}=0.85)$, Cronbach's alpha $(\alpha=0.86)$, and mean variance extracted $(\mathrm{VME}=0.79)$, resulting in values that confirm adequate reliability indices of the instrument in question [60].

\subsection{Procedure}

The research phase began in October 2020, following the suspension of face-to-face classes due to the pandemic. In the first phase, the appropriate permits were requested, from both the Provincial Directorate of Education and Vocational Training of Ceuta. The latter approved and authorized the establishment of the research seminar. Subsequently, the educational centers, with one exception, approved and authorized the development of the seminar. In the second phase, the researchers of this study collected the data by means of a printed questionnaire that was provided to the students of the sixth level of primary education during the first months of the 2020-2021 academic year. The researchers were present during the data collection and advised the students at all times.

Subsequently, in a third phase, once the data had been collected, the database was created in the Statistical Package for the Social Sciences (SPSS), version 28.

\subsection{Data Analysis}

Basic statistical data such as mean (M) and standard deviation (SD) were used in the development of the study. Specific tests were also carried out to determine the distribution, such as Fisher's aiming factor (FA) and Pearson's asymmetry coefficient (PAC). The association of the variables was performed using Pearson's chi-square test $(\chi 2)$, together with Cramer's V (V) and the contingency coefficient (Cont) to determine the associative strength index [61]. In addition, a multiple linear regression model was run to predict the effect of age and gender on students' motivation to use ICT.

\section{Results}

The results obtained after applying the various statistical methods are presented below. In general and descriptively, in Table 1, it can be seen that most of the averages achieved are above the overall mean, i.e., above 2.50. In fact, they were all above 3.00, except for two variables: I forget time when using various electronic devices (INT_1) and exchanging solutions to problems with digital devices with others on the Internet (SOC_2). These were slightly below the average. Going into more detail, the variable with the highest mean was the item using devices at home when they want to (AUT_3). In contrast, the variable with the lowest mean was SOC_2.

Table 1. Descriptive of the scores obtained in the four dimensions.

\begin{tabular}{|c|c|c|c|c|c|c|c|c|c|}
\hline & \multicolumn{5}{|c|}{ Likert Scale $n(\%)$} & \multicolumn{4}{|c|}{ Parameters } \\
\hline & 1 & 2 & 3 & 4 & 5 & $\mathbf{M}$ & SD & $S_{k w}$ & $K_{\text {me }}$ \\
\hline INT_1 & 164 (17.7) & $149(16.1)$ & 339 (36.7) & 125 (13.5) & 147 (15.9) & 2.94 & 1.281 & 0.065 & -0.885 \\
\hline INT_2 & $23(2.5)$ & $34(3.7)$ & 291 (31.5) & $256(27.7)$ & $320(34.6)$ & 3.88 & 1.010 & -0.561 & -0.188 \\
\hline INT_3 & $89(9.6)$ & $75(8.1)$ & $324(35.1)$ & $186(20.1)$ & $250(27.1)$ & 3.47 & 1.238 & -0.392 & -0.659 \\
\hline INT_4 & $57(6.2)$ & $79(8.5)$ & $238(25.8)$ & $205(22.2)$ & 345 (37.3) & 3.76 & 1.213 & -0.652 & -0.513 \\
\hline INT_5 & 182 (19.7) & $137(14.8)$ & $215(23.3)$ & $125(13.5)$ & 265 (28.7) & 3.17 & 1.481 & -0.122 & -1.351 \\
\hline INT_6 & $18(1.9)$ & $29(3.1)$ & $153(16.6)$ & $213(23.1)$ & $511(55.3)$ & 4.27 & 0.974 & -1.26 & 1.049 \\
\hline COM_1 & $174(18.8)$ & $144(15.6)$ & $268(29)$ & 135 (14.6) & $203(22)$ & 3.05 & 1.390 & -0.025 & -1.173 \\
\hline COM_2 & $66(7.1)$ & $56(6.1)$ & $192(20.8)$ & $187(20.2)$ & $423(45.8)$ & 3.91 & 1.243 & -0.923 & -0.162 \\
\hline COM_3 & $21(2.3)$ & $27(2.9)$ & 138 (14.9) & 184 (19.9) & $554(60)$ & 4.32 & 0.983 & -1.44 & 1.531 \\
\hline COM_4 & $83(9)$ & $76(8.2)$ & $282(30.5)$ & 247 (26.7) & $236(25.5)$ & 3.52 & 1.211 & -0.506 & -0.519 \\
\hline COM_5 & $44(4.8)$ & $64(6.9)$ & 209 (22.6) & $190(20.6)$ & 417 (45.1) & 3.94 & 1.175 & -0.854 & -0.208 \\
\hline
\end{tabular}


Table 1. Cont.

\begin{tabular}{|c|c|c|c|c|c|c|c|c|c|}
\hline & \multicolumn{5}{|c|}{ Likert Scale $n(\%)$} & \multicolumn{4}{|c|}{ Parameters } \\
\hline & 1 & 2 & 3 & 4 & 5 & $\mathbf{M}$ & SD & $\mathrm{S}_{\mathrm{kw}}$ & $K_{\mathrm{me}}$ \\
\hline AUT_1 & $202(21.9)$ & $100(10.8)$ & 145 (15.7) & $148(16)$ & $329(35.6)$ & 3.33 & 1.569 & -0.336 & -1.420 \\
\hline AUT_2 & $187(20.2)$ & $130(14.1)$ & $236(25.5)$ & $185(20)$ & $186(20.1)$ & 3.06 & 1.398 & -0.105 & -1.209 \\
\hline AUT_3 & $18(1.9)$ & $34(3.7)$ & 149 (16.1) & $171(18.5)$ & $552(59.7)$ & 4.30 & 0.995 & -0.133 & 1.071 \\
\hline AUT_4 & $148(16)$ & $99(10.7)$ & $242(26.2)$ & $201(21.8)$ & $234(25.3)$ & 3.30 & 1.376 & -0.329 & -1.056 \\
\hline AUT_5 & $69(7.5)$ & $58(6.3)$ & $125(13.5)$ & $195(21.1)$ & 477 (51.6) & 4.03 & 1.255 & -1.16 & 0.231 \\
\hline SOC_1 & $111(12)$ & $104(11.3)$ & 239 (25.9) & $191(20.7)$ & $279(30.2)$ & 3.46 & 1.342 & -0.422 & -0.948 \\
\hline SOC_2 & $362(39.2)$ & 159 (17.2) & 165 (17.9) & 119 (12.9) & 119 (12.9) & 2.43 & 1.436 & 0.527 & -1.099 \\
\hline SOC_3 & $114(12.3)$ & $63(6.8)$ & $154(16.7)$ & $131(14.2)$ & $462(50)$ & 3.83 & 1.422 & -0.868 & -0.628 \\
\hline SOC_4 & $114(12.3)$ & 103 (11.1) & $249(26.9)$ & $187(20.2)$ & $271(29.3)$ & 3.43 & 1.340 & -0.395 & -0.955 \\
\hline SOC_5 & $46(5)$ & $63(6.8)$ & $231(25)$ & $224(24.2)$ & $360(39)$ & 3.85 & 1.158 & -0.750 & -0.255 \\
\hline
\end{tabular}

Note: 1 = Never; 2 = Almost never; 3 = Sometimes; 4 = Almost always; 5 = Always; SD: Standard deviation $\mathrm{S}_{\mathrm{kw}}=$ Asymmetry; $\mathrm{K}_{\mathrm{me}}=$ Kurtosis.

Within the dimension of interest in ICT (INT), the variable with the highest mean score was the item I like using digital devices (INT_6), while the variable with the lowest mean score was INT_1. In the ICT-perceived digital competence (COM) dimension, the variable with the best mean score was I feel comfortable using my digital devices at home (COM_3), while the one with the lowest score was I feel comfortable using digital devices with which I am less familiar (COM_1). In the dimension perceived autonomy through ICT (AUT), the variable with the best mean was I use various electronic devices at home when I want to (AUT_3), while the one with the lowest mean was I read information about digital devices to be independent (AUT_2). Finally, within the dimension of the ICT as a topic of social interaction (SOC), the variable with the highest mean was I learn a lot about digital media when talking to my friends and family (SOC_5), and the one with the lowest mean was SOC_2.

As for the standard deviation, for most of the variables, there was no similar trend in the responses of the respondents, but the respond trend was similar for three variables: I like using digital devices (INT_6), I feel comfortable using my digital devices at home (COM_3), and AUT_3.

On the other hand, the skewness and kurtosis values show that the response distribution was normal. This is because the values were \pm 1.96 , according to [62]. The kurtosis of most of the variables was platykurtic.

Continuing with the correlational analysis (Table 2), there were significant differences in the correlation established between gender and different variables of the commitment to ICT use among sixth-grade primary school students. The variables that showed significant correlations were Internet is a great resource for obtaining information that interests me (INT_2), it is very useful to have social networks (INT_3), I like using digital devices (INT_6), I feel comfortable using digital devices with which I am less familiar (COM_1), when I encounter problems with digital devices, I think I can solve them (COM_4), if I need a new software or program, I install it myself (AUT_5), if I need a new software or program, I install it myself (AUT_6), if I need a new software or program, I install it myself (AUT_6), if I need a new software or program, I install it myself (AUT_6), I install it myself (AUT_1), if I have a problem with digital devices, I start to solve it myself (AUT_4), if I need a new application, I choose it myself (AUT_5), to learn something new about digital devices, I like to talk about them with my friends (SOC_1), SOC_2, I like to get together with friends and play computer and video games with them (SOC_3), and I like to share information about digital devices with my friends (SOC_4). Although there was correlation, the strength of association was low for most of the variables. For SOC_3, the strength of association was medium. In the rest of the variables, there were no statistically significant correlation values. 
Table 2. Association between gender and variables.

\begin{tabular}{|c|c|c|c|c|c|c|}
\hline & \multicolumn{2}{|c|}{ Mean Score for Gender } & \multicolumn{4}{|c|}{ Parameters } \\
\hline & Male & Female & $\chi^{2}(\mathrm{gl})$ & $p$-Value & Cont & $\mathbf{V}$ \\
\hline INT_1 & 2.97 & 2.90 & $7.055(4)$ & 0.133 & 0.087 & 0.087 \\
\hline INT_2 & 3.93 & 3.83 & $15.954(4)$ & 0.003 & 0.130 & 0.131 \\
\hline INT_3 & 3.51 & 3.42 & $13.380(4)$ & 0.010 & 0.119 & 0.120 \\
\hline INT_4 & 3.85 & 3.67 & $5.973(4)$ & 0.201 & 0.080 & 0.080 \\
\hline INT_5 & 3.25 & 3.09 & $6.705(4)$ & 0.152 & 0.085 & 0.085 \\
\hline INT_6 & 4.35 & 4.19 & $15.810(4)$ & 0.003 & 0.130 & 0.131 \\
\hline COM_1 & 3.20 & 2.91 & $13.945(4)$ & 0.007 & 0.122 & 0.123 \\
\hline COM_2 & 3.94 & 3.89 & $7.480(4)$ & 0.113 & 0.090 & 0.090 \\
\hline COM_3 & 4.38 & 4.27 & $9.303(4)$ & 0.054 & 0.100 & 0.100 \\
\hline COM_4 & 3.69 & 3.34 & $19.248(4)$ & 0.001 & 0.143 & 0.144 \\
\hline COM_5 & 3.97 & 3.91 & $5.525(4)$ & 0.238 & 0.077 & 0.077 \\
\hline AUT_1 & 3.45 & 3.20 & $10.325(4)$ & 0.035 & 0.105 & 0.106 \\
\hline AUT_2 & 3.16 & 2.95 & $7.771(4)$ & 0.100 & 0.091 & 0.092 \\
\hline AUT_3 & 4.35 & 4.26 & $8.188(4)$ & 0.085 & 0.094 & 0.094 \\
\hline AUT_4 & 3.47 & 3.13 & $16.096(4)$ & 0.003 & 0.131 & 0.132 \\
\hline AUT_5 & 4.13 & 3.94 & $10.327(4)$ & 0.035 & 0.105 & 0.106 \\
\hline SOC_1 & 3.63 & 3.29 & $23.667(4)$ & 0.000 & 0.158 & 0.160 \\
\hline SOC_2 & 2.65 & 2.21 & $25.842(4)$ & 0.000 & 0.165 & 0.167 \\
\hline SOC_3 & 4.19 & 3.47 & $61.554(4)$ & 0.000 & 0.250 & 0.258 \\
\hline $\mathrm{SOC}_{4} 4$ & 3.59 & 3.27 & $18.679(4)$ & 0.001 & 0.141 & 0.142 \\
\hline SOC_5 & 3.91 & 3.81 & $5.684(4)$ & 0.224 & 0.078 & 0.078 \\
\hline
\end{tabular}

Note: 1 = Never; 2 = Almost never; 3 = Sometimes; 4 = Almost always; 5 = Always; $\chi^{2}$ (gl) = Chi-square, degrees of freedom; $p$-value; Cont $=$ Contingency coefficient; $\mathrm{V}=$ Cramer's V.

In the correlational analysis between age and the variables (Table 3), it was observed that there were variables that showed statistically significant differences in the correlation established between age and the variables I am very excited to discover new digital devices or applications (INT_4), if my friends and family have a problem with digital devices, I can help them (COM_5), INT_2, INT_6, COM_1, COM_3, AUT_3, and AUT_4. Furthermore, it was observed that the strength of association in all of them was low, and the rest of the variables did not show statistically significant signs.

Table 3. Association between age and variables.

\begin{tabular}{lcccccccc}
\hline & \multicolumn{9}{c}{ Average Age } & \multicolumn{5}{c}{ Parameters } \\
\cline { 2 - 9 } & $\mathbf{1 0}$ & $\mathbf{1 1}$ & $\mathbf{1 2}$ & $\mathbf{1 3}$ & $\boldsymbol{\chi}^{\mathbf{2}} \mathbf{( \mathbf { g } )}$ & $\boldsymbol{p}$-Value & $\mathbf{C o n t}$ & $\mathbf{V}$ \\
\hline INT_1 & 2.83 & 2.96 & 2.85 & 2.90 & $6.309(12)$ & 0.900 & 0.082 & 0.048 \\
INT_2 & 3.85 & 3.90 & 3.82 & 3.50 & $21.721(12)$ & 0.041 & 0.152 & 0.089 \\
INT_3 & 3.53 & 3.47 & 3.45 & 3.10 & $9.299(12)$ & 0.067 & 0.100 & 0.058 \\
INT_4 & 3.50 & 3.78 & 3.76 & 3.70 & $23.119(12)$ & 0.027 & 0.156 & 0.091 \\
INT_5 & 3.18 & 3.17 & 3.14 & 3.50 & $18.827(12)$ & 0.093 & 0.141 & 0.082 \\
INT_6 & 4.36 & 4.29 & 4.07 & 4.00 & $29.857(12)$ & 0.003 & 0.177 & 0.104 \\
\hline COM_1 & 2.89 & 3.02 & 3.24 & 3.90 & $21.346(12)$ & 0.046 & 0.150 & 0.088 \\
COM_2 & 3.70 & 3.97 & 3.76 & 3.60 & $20.931(12)$ & 0.051 & 0.149 & 0.087 \\
COM_3 & 4.30 & 4.36 & 4.19 & 3.20 & $36.923(12)$ & 0.000 & 0.196 & 0.115 \\
COM_4 & 3.35 & 3.54 & 3.48 & 3.50 & $13.294(12)$ & 0.348 & 0.119 & 0.069 \\
COM_5 & 3.62 & 3.97 & 3.92 & 4.30 & $32.976(12)$ & 0.001 & 0.186 & 0.109 \\
\hline AUT_1 & 2.95 & 3.33 & 3.47 & 3.90 & $18.639(12)$ & 0.098 & 0.141 & 0.082 \\
AUT_2 & 2.83 & 3.07 & 3.08 & 3.10 & $3.772(12)$ & 0.987 & 0.064 & 0.037 \\
AUT_3 & 4.29 & 4.33 & 4.18 & 3.90 & $21.529(12)$ & 0.043 & 0.151 & 0.088 \\
AUT_4 & 2.98 & 3.32 & 3.32 & 3.40 & $22.971(12)$ & 0.028 & 0.156 & 0.091 \\
AUT_5 & 3.92 & 4.00 & 4.21 & 4.60 & $7.984(12)$ & 0.786 & 0.093 & 0.054 \\
\hline
\end{tabular}


Table 3. Cont.

\begin{tabular}{lcccccccc}
\hline & \multicolumn{9}{c}{ Average Age } & \multicolumn{5}{c}{ Parameters } \\
\cline { 2 - 9 } & $\mathbf{1 0}$ & $\mathbf{1 1}$ & $\mathbf{1 2}$ & $\mathbf{1 3}$ & $\boldsymbol{\chi}^{\mathbf{2}} \mathbf{( \mathbf { g l } )}$ & $\boldsymbol{p}$-Value & Cont & V \\
\hline SOC_1 & 3.26 & 3.46 & 3.49 & 3.90 & $13.009(12)$ & 0.368 & 0.118 & 0.069 \\
SOC_2 & 2.15 & 2.44 & 2.50 & 2.70 & $12.803(12)$ & 0.384 & 0.117 & 0.068 \\
SOC_3 & 3.62 & 3.89 & 3.54 & 3.90 & $12.952(12)$ & 0.373 & 0.118 & 0.068 \\
SOC_4 & 3.02 & 3.49 & 3.34 & 2.80 & $19.599(12)$ & 0.075 & 0.144 & 0.084 \\
SOC_5 & 3.64 & 3.86 & 3.90 & 4.20 & $8.138(12)$ & 0.774 & 0.093 & 0.054 \\
\hline
\end{tabular}

Note: 1 = Never; $2=$ Almost never; $3=$ Sometimes; $4=$ Almost always; $5=$ Always; $\chi^{2}(\mathrm{gl})=$ Chi-square, degrees of freedom; $p$-value; Cont $=$ Contingency coefficient; $\mathrm{V}=$ Cramer's V.

Finally, in the multiple linear regression models, both for gender and for age, the stepwise model was applied. In the analysis applied to gender, five significant models were obtained. In the analysis applied to age, five significant models were also obtained. In both cases, Model 5 was selected, since it had the most significant values (Table 4).

Table 4. Multiple linear regression model by successive steps.

\begin{tabular}{|c|c|c|c|c|c|c|c|}
\hline \multicolumn{8}{|c|}{ Gender } \\
\hline Models & $\mathbf{R}$ & $\mathbf{R}^{2}$ & $\mathbf{R}^{2} \mathbf{C}$ & ETE & $\mathrm{CR}^{2}$ & CF & SCF \\
\hline 1 & 0.255 & 0.065 & 0.064 & 0.484 & 0.065 & 64.306 & 0.000 \\
\hline 2 & 0.270 & 0.073 & 0.071 & 0.482 & 0.007 & 7.420 & 0.007 \\
\hline 3 & 0.279 & 0.078 & 0.075 & 0.481 & 0.005 & 5.343 & 0.021 \\
\hline 4 & 0.289 & 0.083 & 0.079 & 0.480 & 0.005 & 5.435 & 0.020 \\
\hline 5 & 0.297 & 0.088 & 0.083 & 0.479 & 0.005 & 4.607 & 0.032 \\
\hline \multicolumn{8}{|c|}{ Age } \\
\hline Models & $\mathbf{R}$ & $\mathbf{R}^{2}$ & $\mathbf{R}^{2} \mathbf{C}$ & ETE & $\mathrm{CR}^{2}$ & CF & SCF \\
\hline 1 & 0.085 & 0.007 & 0.006 & 0.490 & 0.007 & 6.723 & 0.010 \\
\hline 2 & 0.136 & 0.018 & 0.016 & 0.487 & 0.011 & 10.467 & 0.001 \\
\hline 3 & 0.163 & 0.026 & 0.023 & 0.485 & 0.008 & 7.618 & 0.006 \\
\hline 4 & 0.180 & 0.032 & 0.028 & 0.484 & 0.006 & 5.735 & 0.017 \\
\hline 5 & 0.193 & 0.037 & 0.032 & 0.483 & 0.005 & 4.426 & 0.036 \\
\hline
\end{tabular}

Note: TEE: Standard error of the estimate; $\mathrm{CR}^{2}$ : Changes in $\mathrm{R}^{2}$, CF: Changes in F; SCF: Significance change in F.

In relation to gender, the variables that made up Model 5 (Table 5) were INT_3, the internet is a great resource for information that interests me (e.g., news, sports, and dictionaries) (INT_2), if my friends and family want to buy new digital devices or apps, I can give them advice (COM_2), COM_4, and COM_5. In relation to age, the variables that made up Model 5 were COM_3, if I need a new application, I choose it myself (AUT_5), I feel comfortable using digital devices that I am less familiar with (COM_1), INT_6, and AUT_1. For both gender and age, these variables showed significant values of less than 0.05 . Therefore, these variables showed predictive value, although their predictive ability was low.

Table 5. Coefficients of the multiple linear regression of gender and age.

\begin{tabular}{cccccc}
\hline \multicolumn{5}{c}{ Gender } \\
\hline & B & Typical Error & Beta & t & Sig. \\
\hline 5 (Constant) & 1.824 & 0.069 & & 26.404 & 0.000 \\
INT_3 & -0.085 & 0.012 & -0.243 & -6.962 & 0.000 \\
INT_2 & -0.033 & 0.012 & -0.094 & -2.827 & 0.005 \\
COM_2 & 0.025 & 0.015 & 0.061 & 1.662 & 0.097 \\
COM_4 & -0.043 & 0.015 & -0.104 & -2.909 & 0.004 \\
COM_5 & 0.036 & 0.017 & 0.083 & 2.146 & 0.032 \\
\hline
\end{tabular}


Table 5. Cont.

\begin{tabular}{cccccc}
\hline \multicolumn{7}{c}{ Age } \\
\hline B & Typical Error & Beta & t & Sig. \\
\hline 5 (Constant) & 2.202 & 0.086 & & 25.481 & 0.000 \\
COM_3 & -0.054 & 0.019 & -0.107 & -2.799 & 0.005 \\
AUT_5 & 0.033 & 0.014 & 0.084 & 2.277 & 0.023 \\
COM_1 & 0.038 & 0.012 & 0.107 & 3.110 & 0.002 \\
INT_6 & -0.050 & 0.019 & -0.098 & -2.573 & 0.010 \\
AUT_1 & 0.023 & 0.011 & 0.075 & 2.104 & 0.036 \\
\hline
\end{tabular}

\section{Discussion}

COVID-19 has markedly changed the use of ICTs in homes and in the educational field [6-8,43]. Here, we studied the concerns and motivations of students in the sixth year of primary education in relation to access, use, and commitment to ICTs, which go beyond the barriers of schools [13]. The results provide important information for families and teachers, in line with what was established by Skvarc et al. (2021). Those students who have had technological resources at their disposal have improved their digital competence [16]. Moreover, it has enabled them to have a more standardized learning process. On the other hand, those who did not have technological resources at their disposal saw a decrease in their performance [25-27]. As Vila et al. (2020) did, we highlighted two key elements in this study: the role of ICT in students from 10 to 13 years old and the influence of gender, both in schools and in homes, as well as in their academic performance.

This research showed a similar response trend in certain variables. In other words, there is a similar opinion on the part of all those involved in the perceived autonomy in the use of ICTs, in the interest generated by their use, in perceived digital competence, and in the use of ICTs for social interaction [1-3].

Regarding the first objective of the study, during and after confinement, the educational community (teachers, families, and students) has given greater recognition to the knowledge and use of ICT $[26,27,51]$. This use has been associated with increased academic performance and motivation $[18,19]$, but with nuances. In those adolescents who are supervised in the use of ICT by their families and, in addition, use ICT as a methodological resource in schools, there are benefits in their academic performance $[15,16,36,45]$. However, those who use electronic tools and devices without supervision, as a means of recreation, socializing, or sharing multimedia images [13], decline in terms of their performance in mathematics, science, and reading comprehension [5,49].

This is a clear example of how certain factors influence students' ICT use. This study analyzed the influence of gender and age on ICT use and engagement after the pandemic. Starting with the analysis of the results obtained, it was generally observed that the assessment of ICT use and engagement in the educational environment was medium-high. This is in line with other studies [5,45-50]. It is true that certain aspects were below the overall average, as in the case where students forget about time when using electronic devices or where they exchange solutions to problems with digital devices using the Internet. This may be due to a lack of socialization during the pandemic period. As can be seen, not all aspects of ICT use are positive [26-28].

It has been shown that students who like the use of digital devices feel comfortable with their use at home [3-5,26,36]. In addition, they make use of ICT when they consider it appropriate and improve their digital competence when they debate with other people, as stated by Aesaert et al. (2015), Gniewosz et al. (2014), and Senkbeil et al. (2016). From a less positive perspective, students felt more insecure when using new, unfamiliar digital devices, forcing them to exchange solutions to problems with digital devices with others on the Internet. They also had minor difficulties when reading information about the use of certain digital devices in order to be independent. In other words, all of the circumstances mentioned are involved when students had to solve problems using ICT. This is in line with other studies $[5,11,26,27]$. 
In relation to the second objective, the influence of the use and commitment of ICTs on gender, the results for all variables showed a greater predisposition on the part of boys, contrary to what was observed by López et al. (2019). This is in line with the results obtained by Vekiri (2013) and Vila et al. (2020), in which boys found it very useful to have social networks, they liked to get together with friends and play computer and video games, and they also liked to share information about digital devices with their friends. The results of this research showed that the Internet was used as a resource for information that interests the student more so in boys, a fact that is contrary to other research data such as that of López et al. (2019) and Vekiri (2013). Although the correlation was low, there was an exceptionally medium correlation with the enjoyment of meeting friends and playing computer and video games in male students, compared to the female group.

In relation to gender, boys were more likely to have access to the Internet as a resource for obtaining information, using social networks, solving problems with devices, and giving advice to friends and family when they want to buy something or solve problems with digital devices or applications. These results follow what was established by Botuzova (2020) and López et al. (2019). Admittedly, the predictive factor was low, but high enough to be taken into account.

Finally, in relation to the third objective, in relation to age, a low correlation between age and various variables was observed, due to possible economic differences, digital skills, or the presence of electronic devices in the home, which the sample presents, as also established by Martínez and Fierros (2022). In this case, the variable representing being excited about discovering new digital devices was similar at ages 11-13. However, at the age of 10, these values were lower. With regard to whether their friends and family have a problem with digital devices and whether they can help them, students aged 13 had a higher rating than the rest of the age groups, supporting the results of Christoph (2015), Díaz et al. (2020), Moreno (2019), and Murillo and D'Antonio (2019).

The same was true for adolescents and the feeling of comfort with using digital devices with which they are less familiar. Moreover, they stated that, if they have a problem with them, they start to solve it themselves. Regarding how they like to use digital devices, they felt comfortable using them at home whenever they wanted, considering the Internet a great resource for information (e.g., news, sports, and dictionaries). This fact may be related to the reason for distancing during the pandemic, as established by Serra et al. (2021). By contrast, 13-year-old students rated it lower than other age groups did, in line with the results of other studies [1,5,25,38,40,55].

In pupils aged 10-13 years, age correlated with the variables of liking to use digital devices, feeling comfortable at home with ICT, choosing one's own applications if needed, feeling comfortable using digital devices with which they are less familiar, and installing a new software or program, as established by Castellano and Pantoja (2017), Karapanos and Hawlitschek (2021), and Segura et al. (2020). As with gender, the prediction was low, but high enough to be taken into account. In this case, liking and feeling comfortable using digital devices at home among 13-year-old students was rated worse than the rest of the age groups. On the other hand, if they need a new application, software, or program, they are more likely to choose and install it themselves, and they feel more comfortable using digital devices with which they are less familiar, compared to the other age groups.

Importantly, this study confirms that both gender and age are predictive factors in the engagement of ICT use in teaching and learning processes following the studies by Segura et al. (2020) and Stuchlikova (2016).

\section{Conclusions}

In relation to the first objective, it can be concluded that the use and commitment of ICT in students in the sixth year of primary education in the Spanish context, after the period of confinement, was medium-high. Taking the second objective as a reference, the male gender presented a higher value in the use of ICT than the female gender. Lastly, in relation to the third objective, 13-year-old students presented scores below the rest of 
the age groups analyzed in terms of, e.g., feeling comfortable using digital devices at home. In addition, in both gender and age, there was a correlation allowing us to offer predictive elements.

Therefore, the results of this study and the increasing levels of ICT use, as pointed out by Skvarc et al. (2021), suggest a need to guarantee access to ICT and its productive use to students, both in schools and at home, because we are immersed in an ecosystem of educational innovation, given the global impact of COVID-19, as also established by Martínez and Fierros (2022).

The pandemic has made it possible to discover the differences generated by the use of ICTs in different homes and their use and motivations among adolescents. This fact should not go unnoticed by educational policies that must address and compensate for these differences from the classroom, in order to face the challenges that are here to stay: an education and, above all, a digitized society. Therefore, we are facing an uncertain future in relation to perceived digital competence following the line of research by Vila et al. (2020).

Among the main limitations of this study is the focus of the sample chosen, specifically the sixth year of primary education, which includes a variable age range between 10 and 13 years old, with different percentages of participation, the largest sample being the 11year-old age group. The fact that we were unaware of the pandemic situation and its consequences, and did not carry out a pre-test and post-test, does not allow us to establish the real impact that the confinement has had on the students in the sample.

The prospective results from this research focus on the use and commitment of adolescents in the primary education stage and their willingness, skills, and commitment to a possible hybrid education in the future. At the same time, following this study, teachers and families should become aware that ICT is a real resource today and is indispensable in the daily lives of children from an early age, both at school and at home.

As future lines of research, we are considering the possibility of selecting other educational levels and stages, in order to detect the beginnings of the evolution of the use of and commitment to ICT. In addition, their relationships with other variables, such as the possession of electronic devices, socio-demographic data, and the use of social networks, and their influence on results can be assessed.

Author Contributions: Conceptualization, P.D.-T., A.-J.M.-G., J.-A.M.-M.; methodology, P.D.-T., A.J.M.-G., J.-A.M.-M.; software, A.-J.M.-G.; formal analysis, P.D.-T., A.-J.M.-G., J.-A.M.-M.; investigation, P.D.-T., A.-J.M.-G., J.-A.M.-M.; data curation, P.D.-T., A.-J.M.-G.; writing original draft preparation, P.D.-T., A.-J.M.-G.; writing-review and editing, P.D.-T., A.-J.M.-G.; visualization, A.-J.M.-G.; supervision, A.-J.M.-G. All authors have read and agreed to the published version of the manuscript.

Funding: This research did not receive external funding. It corresponds to a study as part of a doctoral thesis at the University of Granada.

Conflicts of Interest: The authors declare that they have no conflict of interest.

\section{Appendix A}

Table A1. ICT participation questionnaire. Areas and variables.

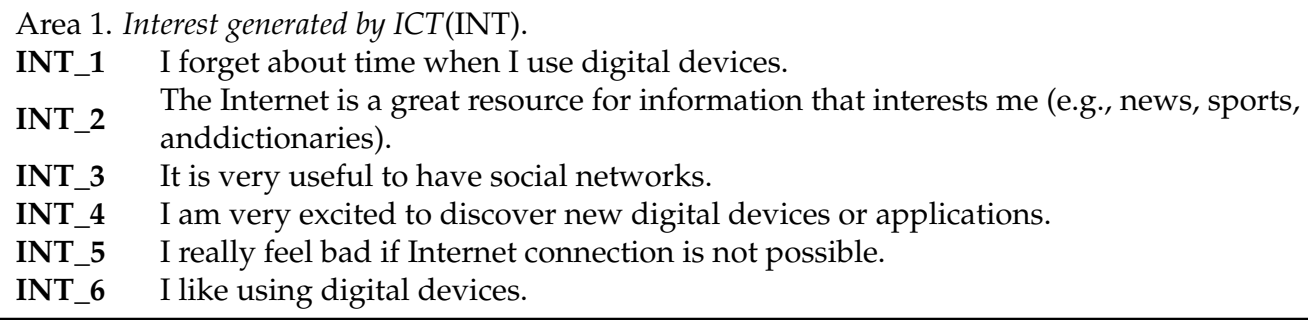


Table A1. Cont.

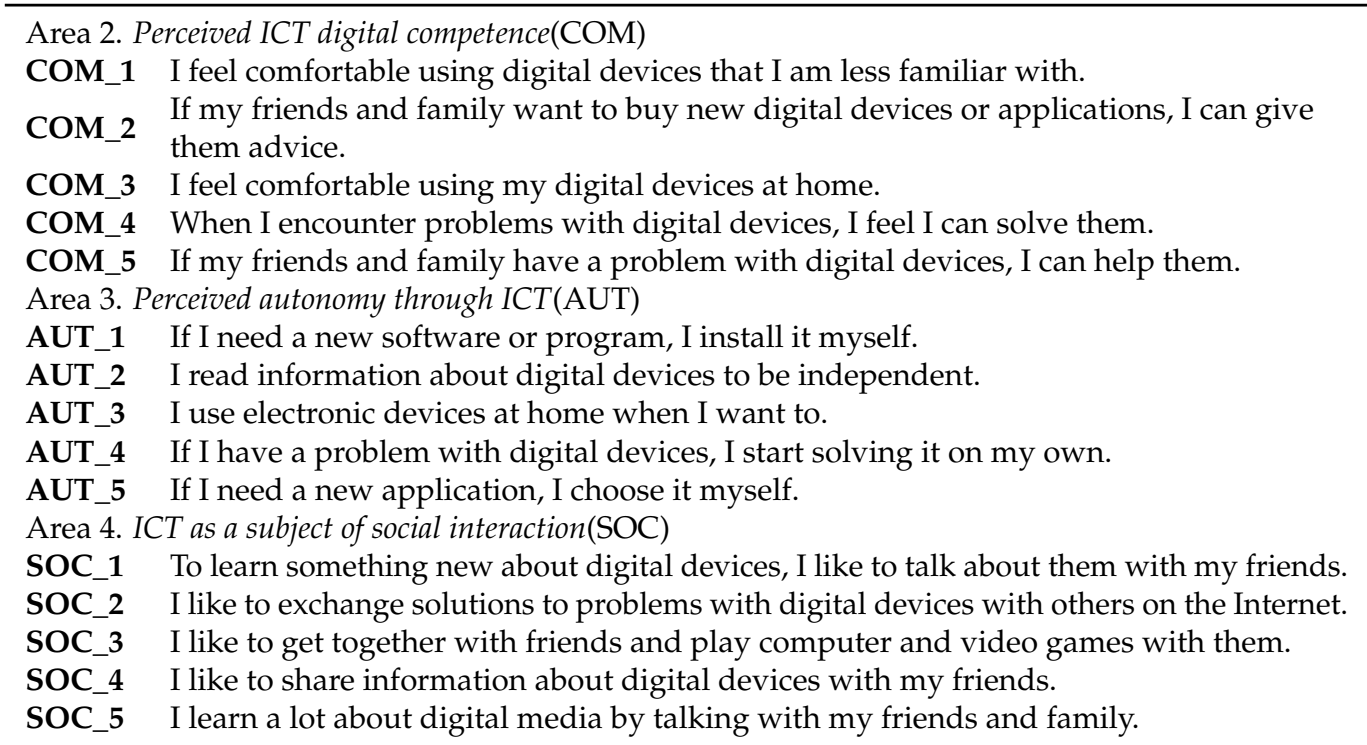

\section{References}

1. Castellano, E.A.; Pantoja, A. Efficacy of an intervention program based on the use of ICT in tutoring. J. Educ. Res. 2017, 35, 215-233.

2. López, J.; Pozo, S.; Fuentes, A.; Vicente, M. Popular games as a teaching resource for the improvement of healthy living habits in the digital time. Retos 2019, 36, 266-272. [CrossRef]

3. Drakopoulos, V.; Vlasios, P. Enhancing Primary School Teaching through Virtual Reality. J. Comput. Sci. Res. 2021, 3, 2. [CrossRef]

4. Gómez, N.; Mediavilla, M. Exploring the relationship between Information and Communication Technologies (ICT) and academic performance: A multilevel analysis for Spain. Socio-Econ. Plan. Sci. 2021, 77, 101009. [CrossRef]

5. Serra, G.; Lo Scalzo, L.; Giuffrè, M.; Ferrara, P.; Corsello, G. Smartphone use and addiction during the coronavirus disease 2019 (COVID-19) pandemic: Cohort study on 184 Italian children and adolescents. Ital. J. Pediatr. 2021, 47, 150. [CrossRef]

6. Panskyi, T.; Korzeniewska, E.; Serwach, M.; Grudzień, K. New realities for Polish Primary School informatics education affected by COVID-19. Educ. Inf. Technol. 2021, 1, 28. [CrossRef]

7. Borgonovi, F.; Pokropek, M. The Evolution of the Association between ICT Use and Reading Achievement in 28 Countries; (No. 21-14); Quantitative Social Science-UCL Social Research Institute, University College London: London, UK, 2021.

8. Moreno-Guerrero, A.J.; Soler-Costa, R.; Marín-Marín, J.A.; López-Belmonte, J. Flipped learning and good teaching practices in secondary education. Comunicar 2021, 29, 107-117. [CrossRef]

9. Moreno, A.J.; López, J.; Pozo, S.; Fuentes, A. Influence of the context in the use of ICT devices in Basic Vocational Training. EDMETIC 2019, 9, 149-169. [CrossRef]

10. Díaz, A.; Maquilón, J.; Mirete, A.B. Maladaptive use of ICT in adolescence: Profiles, supervision and technological stress. Comunicar 2020, 28, 29-38. [CrossRef]

11. Murillo, F.; D'Antonio, S. ICT, young people and social work: Distances and opportunities. Soc. Work Educ. 2019, 39, 813-824. [CrossRef]

12. Moreno-Guerrero, A.J.; Miaja Chippirraz, N.; Bueno-Pedrero, A.; Borrego-Otero, L. The information and information literacy area of the digital teaching competence. Rev. Electrón. Educ. 2020, 24, 1-16. [CrossRef]

13. Vila, E.; Rodríguez, A.; Martínez, E. Digital competence of galician preteens before the pandemic: What now? Rev. Latinoam. Tecnol. Educ. 2020, 19, 9-27. [CrossRef]

14. Hietajärvi, L.; Tuominen, H.; Hakkarainen, K.; Salmela, K.; Lonka, K. Is Student Motivation Related to Socio-digital Participation? A Person-oriented Approach. Procedia Soc. Behav. Sci. 2014, 171, 1156-1167. [CrossRef]

15. Ghobadi, S.; Ghobadi, Z. How access gaps interact and shape digital divide: A cognitive investigation. Behav. Inf. Technol. 2015, 34, 330-340. [CrossRef]

16. McCahey, A.; Allen, K.A.; Arslan, G. Information communication technology use and school belonging in Australian high school students. Psychol. Sch. 2021, 58, 2392-2403. [CrossRef]

17. Zaranis, N. Geometry Teaching Through ICT in Primary School. Semant. Sch. 2014, 59-71. [CrossRef]

18. Delić, A.; Gadžo, N. Implementation of ICT in Education. In Advanced Technologies, Systems, and Applications II; Hadžikadić, M., Avdaković, S., Eds.; IAT 2017; Lecture Notes in Networks and Systems, 28; Springer: Cham, Switzerland, 2018. [CrossRef]

19. Veiga, F.J.M.; Andrade, A.M.V. Critical Success Factors in Accepting Technology in the Classroom. Int. J. Emerg. Technol. Learn. (iJET) 2021, 16, 4-22. [CrossRef] 
20. Aesaert, K.; Nijlen, D.; Vanderlinde, R.; Tondeur, J.; Devlieger, I.; Van Braak, J. The Contribution of Pupil, Classroom and School Level Characteristics to Primary School Pupils' ICT Competences: A Performance-based Approach. Comput. Educ. 2015, 87, 55-69. [CrossRef]

21. Senkbeil, M.; Ihme, J.M.; Schöber, C. How well are prospective and advanced students prepared for living and working in the digital world? Results of a standard setting procedure for the description of ICT-related competence levels. J. Educ. 2019, 22, 1359-1384. [CrossRef]

22. Pons, J.P.; Llorent, M. Teachers' and students' emotions in the interaction with technology in schools with codes of ICT best practices. XXI Century Educ. 2022, 38, 155-170.

23. Ochoa, M.B.; Correa, J.M.; Gutiérrez, A. ICT in attention to educational diversity: The case of the Basque Autonomous Community. Rev. Educ. Distancia (RED) 2019, 19, 61. [CrossRef]

24. Sola, T.; Cáceres, M.P.; Romero, J.J.; Ramos, M. Bibliometric study of documents indexed in Scopus on ICT Teacher Training related to Educational Quality. Interuniv. Electron. J. Teach. Train. 2020, 23, 19-35. [CrossRef]

25. Gubbels, J.; Swart, N.; Groen, M. Everything in moderation: ICT and reading performance of Dutch 15-year-olds. Large-scale. Assess. Educ. 2020, 8, 1-17. [CrossRef]

26. Lepičnik, J.; Bagon, S. Motivation for Using ICT and Pupils with Learning Difficulties. Int. J. Emerg. Technol. Learn. (iJET) 2016, 11, 70-75. [CrossRef]

27. Romero, M.; López, M.; Pichardo, M.C. Neurophysiological Maturity and the Use of ICT in Teaching English. Electron. J. Res. Educ. Psychol. 2019, 17, 27-54.

28. Jamieson, R.; Finger, G. Measuring and Evaluating ICT Use: Developing an Instrument for Measuring ICT Use. In Handbook of Research on New Media Literacy at the K-12 Level: Issues and Challenges; IGI Global: Hershey, PA, USA, 2009. [CrossRef]

29. Andyani, H.; Setyosari, P.; Wiyono, B.; Djatmika, E. Does Technological Pedagogical Content Knowledge Impact on the Use of ICT In Pedagogy? Int. J. Emerg. Technol. Learn. (iJET) 2020, 15, 126. [CrossRef]

30. Wang, X.; Dostál, J. An analysis of the integration of ICT in education from the perspective of teachers' Attitudes. In Proceedings of the 9th International Conference on Education and New Learning Technologies, Barcelona, Spain, 3-5 July 2017; pp. 8156-8162. [CrossRef]

31. Gutiérrez, H.; Aristizabal, J.H.; Rincón, J.A. Visualization processes in the resolution of mathematical problems at the basic primary level supported by ICT-mediated learning environments. Sophia 2020, 16, 120-132. [CrossRef]

32. Zubiria, E.; Vallet, I.; Bel, I.; Benítez, J. Improvement of the learning process through the use of a mobile-learning methodology in higher education. In Proceedings of the 13th International Technology, Education and Development Conference, Valencia, Spain, 11-13 March 2019; pp. 6911-6916. [CrossRef]

33. Stuchlikova, L. Challenges of education in the 21st century. In Proceedings of the 2016 International Conference on Emerging eLearning Technologies and Applications (ICETA), Stary Smokovec, Slovakia, 24-25 November 2016; pp. 335-340. [CrossRef]

34. Segura, A.G.; Paniagua, F.J.; Fernández, M. Methodology to evaluate university communication on Facebook and Twitter. Soc. Prism Mag. 2020, 28, 127-144.

35. Vekiri, I. Information science instruction and changes in girls' and boy's expectancy and value beliefs: In search of gender-equitable pedagogical practices. Comput. Educ. 2013, 64, 104-115. [CrossRef]

36. Ihme, J.M.; Senkbeil, M. Why adolescents cannot realistically assess their own computer-related skills. J. Dev. Educ. Psychol. 2017, 49, 24-37. [CrossRef]

37. Delić, A. Modern Teaching Approaches. In Advanced Technologies, Systems, and Applications II; Hadžikadić, M., Avdaković, S., Eds.; IAT 2017; Lecture Notes in Networks and Systems, 28; Springer: Cham, Switzerland, 2018. [CrossRef]

38. Blau, I.; Shamir, T.; Hadad, S. Digital collaborative learning in elementary and middle schools as a function of individualistic and collectivistic culture: The role of ICT coordinators' leadership experience, students' collaboration skills, and sustainability. J. Comput. Assist. Learn. 2020, 36, 672-687. [CrossRef]

39. Senkbeil, M. Development and validation of the ICT motivation scale for young adolescents. Results of the international school assessment study ICILS 2013 in Germany. Learn. Individ. Differ. 2018, 67, 167-176. [CrossRef]

40. Gniewosz, G.; Goldhammer, F.; Zylka, J.; Hartig, J. Adolescents' computer performance: The role of self-concept and motivational aspects. Comput. Educ. 2014, 81, 1-12. [CrossRef]

41. Martínez, M.; Fierros, I. Determinants of internet use by school-age children: The challenges for Mexico during the COVID-19 pandemic. Telecomm. Policy 2022, 46, 102241. [CrossRef] [PubMed]

42. Botuzova, Y.V. Experience of using ICT tools for teaching mathematical analysis to future teachers of mathematics. ICT and learning tools in the higher education establishments. Inf. Technol. Learn. Tools 2020, 75, 153-169. [CrossRef]

43. Skvarc, D.R.; Talbot, M.; Harries, T.; Wilson, C.J.; Joshua, N.; Byrne, L.K. Home Information and Communication Technology Use and Student Academic Performance: Encouraging Results for Uncertain Times. Front. Psychol. 2021, 12, 2121. [CrossRef]

44. Kunina, O.; Goldhammer, F. ICT Engagement: A new construct and its assessment in PISA 2015. Large-Scale Assess. Educ. 2020, 8, 6. [CrossRef]

45. Vazquez, V.; Huerta, E.L. Factors Related with Underperformance in Reading Proficiency, the Case of the Programme for International Student Assessment 2018. Eur. J. Investig. Health Psychol. Educ. 2021, 11, 813-828. [CrossRef]

46. Ma, Y.; Qin, X. Measurement invariance of information, communication and technology (ICT) engagement and its relationship with student academic literacy: Evidence from PISA 2018. Stud. Educ. Eval. 2021, 68, 100982. [CrossRef] 
47. Lezhnina, O.; Kismihók, G. Combining statistical and machine learning methods to explore German students' attitudes towards ICT in PISA. Int. J. Res. Method Educ. 2021, 1-14. [CrossRef]

48. Odell, B.; Cutumisu, M.; Gierl, M.A. Scoping review of the relationship between students' ICT and performance in mathematics and science in the PISA data. Soc. Psychol. Educ. 2020, 23, 1449-1481. [CrossRef]

49. Kaya, V.H.; İnci, S. How does Information and Communications Technology Influence Turkish Students' Science Achievement? J. Comput. Educ. Res. 2021, 9, 754-770. [CrossRef]

50. Özkan, B.; Noyan, F. The effects of information and communication technology engagement factors on science performance between Singapore and Turkey using multi-group structural equation modelling. J. Balt. Sci. Educ. 2021, 20, 639-650. [CrossRef]

51. Karapanos, M.; Hawlitschek, P. Advantage through technology? On the role of technology readiness and technology equipment for studying from home. Educ. Res. J. 2021, 11, 567-587. [CrossRef]

52. Srijamdee, K.; Pholphirul, P. Does ICT familiarity always help promote educational outcomes? Empirical evidence from PISA-Thailand. Educ. Inf. Technol. 2020, 25, 2933-2970. [CrossRef]

53. Moreno, A.J.; Alonso, S.; Ramos, M.; Campos, M.N.; Gómez, G. Augmented Reality as a Resource for Improving Learning in the Physical Education Classroom. Int. J. Environ. Res. Public Health 2020, 17, 3637. [CrossRef]

54. Pereira, E.; Marques, K. The Student Monitoring the Computer Room as a strategy for the pedagogical use of ICT in the Municipal Schools of Santa Maria. Educacao 2020, 45, 1-28. [CrossRef]

55. Corujo Vélez, C.; Gómez del Castillo, M.T.; Merla González, A.E. Construtivist and collaborative methodology mediated by ICT in Higher education. Pixel-Bit. Rev. Medios Educ. 2020, 57, 7-57. [CrossRef]

56. Mailizar, A.; Maulina, S.; Bruce, S. Secondary School Mathematics Teachers' Views on E-learning Implementation Barriers during the COVID-19 Pandemic: The Case of Indonesia. Eurasia J. Math. Sci. Technol. Educ. 2020, 16, 9. [CrossRef]

57. Hernández, R.; Fernández, C.; Baptista, P. Definition of the scope of the research to be carried out: Exploratory, descriptive, correlational or explanatory. In Investigation Methodology, 6th ed.; McGraw Hill: Ciudad de Mexico, Mexico, 2014 ; pp. 88-101.

58. Government School Council. 2019 Report on the State of the Educational System Ceuta and Melilla Course 2017-2018; Ministry of Education and Vocational Training: Madrid, Spain, 2019. [CrossRef]

59. Cabero, J.; Infante, A. Use of the Delphi method and its use in communication and education research. Edutec. Electron. J. Educ. Technol. 2014, 48, 1-16. [CrossRef]

60. Bisquerra, R. Educational Research Methodology. La Muralla. 2004. Available online: https://www.academia.edu/38170554 /metodolog\%c3\%8da_de_la_investigaci\%c3\%93n_educativa_rafael_bisquerra_pdf (accessed on 12 October 2021).

61. Moreno, A.J.; López, J.; Pozo, S.; López, J.A. Usability and prospective of distance learning in Vocational Training determined by digital competence. Aula Abierta 2021, 50, 471-480. [CrossRef]

62. Jöreskog, K.G. Analysisof ordinal variables 2: Cross-Sectional Data. In Text of the Workshop "Structural Equation Modelling with LISREL 8.51"; Friedrich-Schiller-Universität Jena: Jena, Germany, 2001; pp. 116-119. 